\title{
The Hawaii Marine Laboratory ${ }^{1}$
}

\author{
ROBERT W. HIATT ${ }^{2}$
}

\section{INTRODUCTION}

The Coconut IsLAND BRANCH of the Hawaii Marine Laboratory was officially opened on April 21, 1951, with an exhibit of research in progress and equipment utilized in the marine sciences. The Hawaii Marine Laboratory is an integral part of the University of Hawaii and consolidates under one name the long-established Marine Biological Laboratory at Waikiki Beach, the biological laboratories devoted to marine sciences on the main campus of the University, and the newly constructed branch at Coconut Island. The Laboratory operates for both teaching and research, with the Waikiki branch and the classrooms and laboratories on the main campus of the University devoted primarily to instruction, and the Coconut Island branch devoted exclusively to research. These new facilities greatly enhance the effectiveness of both the academic program in marine and fishery biology leading to the bachelor's, master's, and doctor's degrees, and the research program in marine sciences of the graduate students and regular staff. Physical separation of instruction and research has now been achieved so that neither interferes with the other. A well-integrated instructional program in marine biology may now be carried out throughout the year at the reef edge at the Waikiki branch, while research projects may proceed without interruption throughout the year at the Coconut Island branch.

The generous loan of unexcelled facilities for marine research by Messrs. Allan Chase, Edwin Pauley, Harold Pauley, Poncet Davis,

${ }^{1}$ Contribution No. 8, Hawaii Marine Laboratory.

${ }^{2}$ Department of Zoology and Entomology, University of Hawaii. Manuscript received June 15, 1951. and Samuel Mosher made it possible to extablish the Coconut Island branch. Through funds provided by Mr. Edwin Pauley and the University of Hawaii, this Laboratory and associated ponds and aquaria have been completed and put into operation.

The Laboratory operates throughout the year, but more space is available for visiting investigators during the regular academic year than during the summer period.

Since the Coconut Island branch has been established for strictly research purposes, only persons prosecuting some specific study leading to eventual scientific publication, or an assistant of such a person, will be accommodated. Naturally, staff members of the University of Hawaii will have priority for available space. A cooperative agreement entered into by the University of Hawaii and the University of California for the purposes of mutual assistance in marine research in the central Pacific provides second priority to interested members of the staff of the latter institution. The remaining space is available to other marine scientists. All requests for space must be made on an application form available from the Director. Visiting investigators are welcome and all possible aid will be provided them by the staff of the Laboratory. Such laboratory facilities and housing as are available to visiting investigators bear no fee, except where expendable supplies are concerned. A brochure describing the Laboratory and the regulations for visiting investigators. is available from the Director.

\section{COCONUT ISLAND BRANCH}

Location: Coconut Island, known to $\mathrm{Ha}$ waiians as Moku-o-loe, is situated in the pro- 


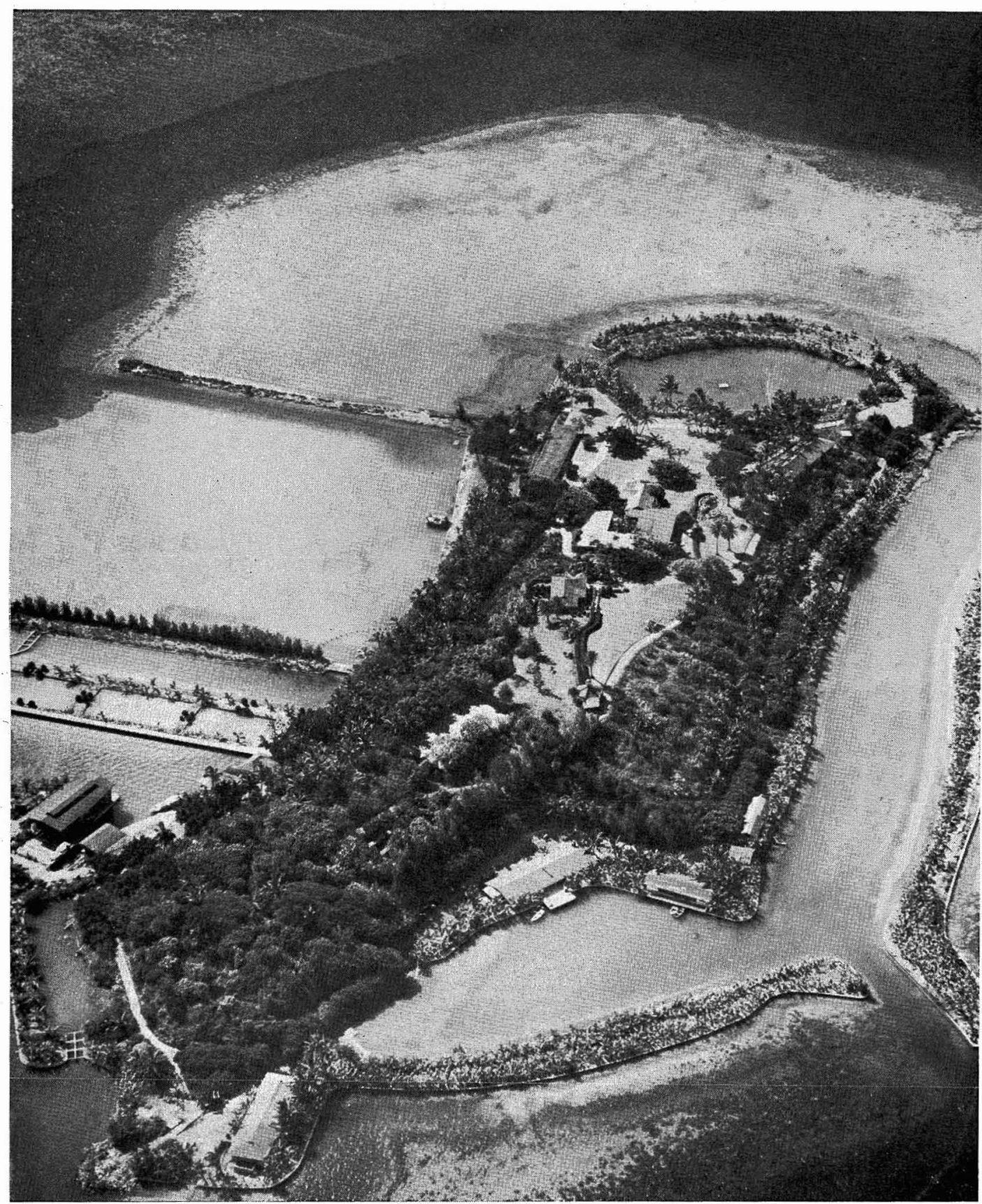

FIG. 1. Aerial view of Coconut Island, showing the Marine Laboratory (lower center) and the tidal pools (middle left). 
tected waters of Kaneohe Bay, about 15 miles from Honolulu, and about 200 yards off the windward shore of Oahu (Fig. 1). Containing a total of 18 acres of land, this verdant island is surrounded by numerous lagoons and pools dredged in the fringing reef. Kaneohe Bay, about 15 square miles in extent, opens broadly to the sea over a protective, elevated reef. The northeast trade winds sweep directly into the bay, thus forcing a rapid exchange of the bay and oceanic waters, which provides for ranges of salinity varying from brackish conditions close to stream mouths to almost normal ocean conditions in the more open areas.

Much of the peripheral region of the bay, especially near the mouths of intermittent streams, is muddy. The organic content of these sandy and muddy areas is high, and it supports an extensive marine fauna. The central part of the bay consists of many channels of varying widths surrounding coral platforms which reach the surface of the water at low tide. Each coral platform is fringed by an extensive growth of corals, principally Porites compressa and species of Montipora, comprising the finest development of coral growth in the Hawaiian Islands. The eroding tops of these coral platforms contain isolated coral heads interspersed with a fine, silty sand composite. The sides of the channels below 4 fathoms and the bottoms of the channels at an average of 7 fathoms consist of very fine silt. There are many coral heads and intervening sandy areas on the fringing reef platform surrounding Coconut Island, thus providing one of the richest collecting grounds in Hawaii. Contributing greatly to the varied ecological situations in the vicinity of Kaneohe Bay are the true oceanic conditions found just outside the bay, within half an hour's boat trip from the Laboratory.

Fauna and flora: Hawaii is situated at the extreme eastern periphery of the richest faunal area known, the Indo-Pacific. Over 2,000 species of invertebrates and over 500 species of fish inhabit the reef and inshore areas. The
Laboratory and its environs offer ideal facilities for studies on all phases of the biology of tropical and subtropical fish, turtles, and invertebrates. Comparatively little is known about the biology of such animals so there is great latitude in the selection of research problems. The zooplankton of the bay waters and the neritic waters just outside the bay is exceedingly varied and abundant in contrast with the oceanic waters farther from shore. The finest oceanic bird rookery in the Hawaiian Archipelago, excepting some of the Leeward Hawaiian Islands, is located just outside Kaneohe Bay on the islet of Moku Manu: a half-hour boat trip from the Laboratory places the observer upon an unparalleled outdoor laboratory for studies on several species of terns, shearwaters, petrels, boobies, and frigate birds.

Hawaiian shores abound in algae of all major groups. Especially abundant are chlorophycean genera such as Ulva, Cladophora (a variable genus with many representatives), Caulerpa, Codium, and Halimeda. The last four genera offer special possibilities as subjects for physiological research, Cladophora because it is large-celled and filamentous, Caulerpa and Codium because they are unicellular, and the unicellular Halimeda because it produces abundant calcareous deposits. Among the Phaeophyceae prominent genera are Ectocarpus, Sargassum, Padina, and Stictyota. The red algae are represented by many genera, perhaps the most abundant of which are Laurencia, Rbodymenia, Liagora (mostly calcareous), and the corallines. The agariferous genus Gelidium is of special interest. The bluegreen algae and the diatoms are, of course, abundant.

Property: The buildings, ponds, docks, and repair facilities occupy the leeward fringe of Coconut Island. In addition to the laboratory itself, there are a residence hall, net house, dock, marine railway, six tidal ponds of varying dimensions and depths (Fig. 2), a battery of large glass-fronted aquaria, and five large partially sunken concrete tanks 


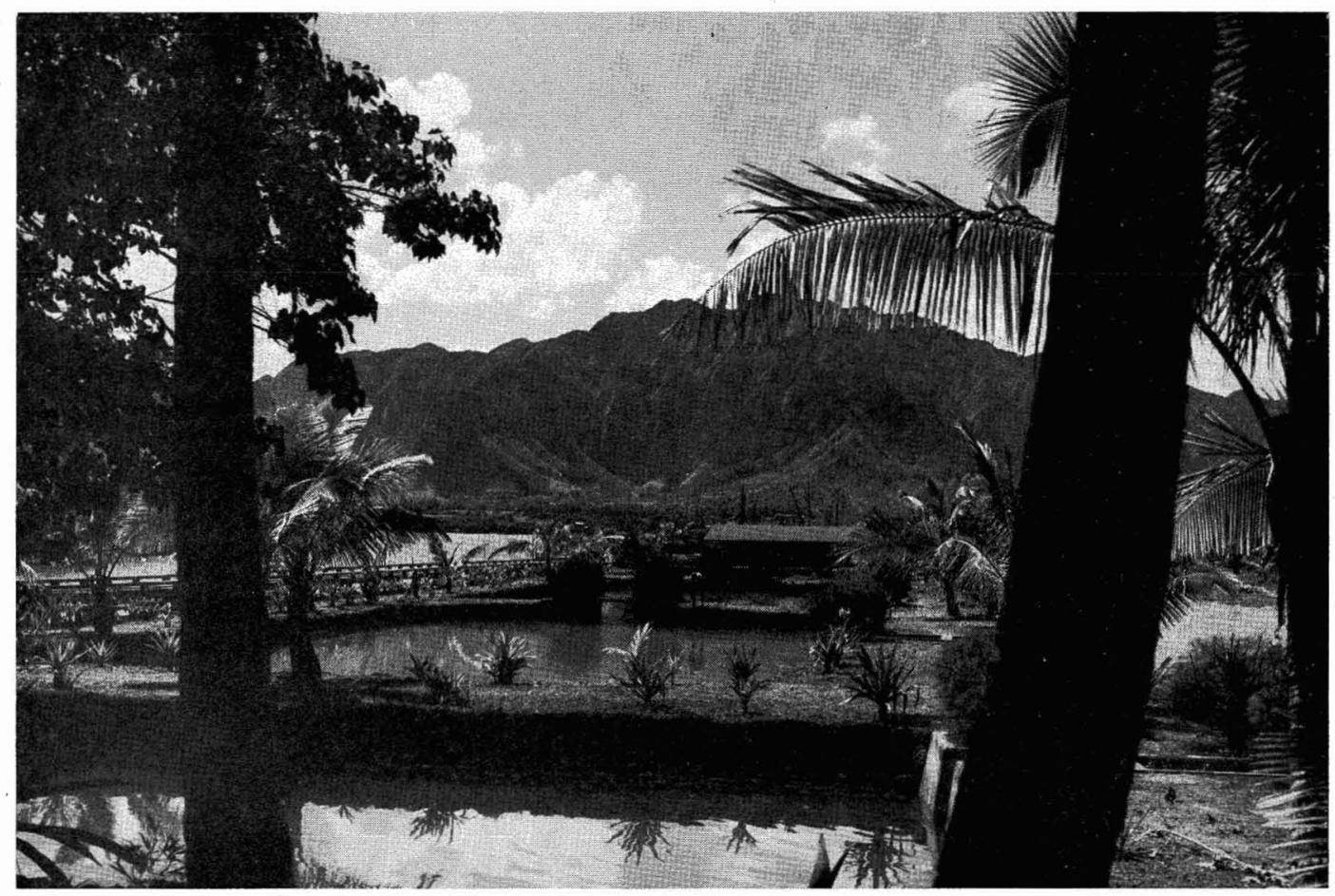

FIG. 2. View of some tidal ponds.

with an aggregate capacity of 20,000 gallons. The aquaria and tanks are provided with circulating sea water by a pumping plant separate from that which supplies the system in the laboratory building.

Laboratory and auxiliary buildings: The laboratory building (Figs. 3, 4) faces southeast and borders a large dredged lagoon. The dock is connected to the laboratory structure with a concrete lanai, thus facilitating the transfer of living specimens from the live well of the laboratory's research vessel, the Salpa, to the aquarium tables of the laboratory just 30 feet away. Collecting gear and supplies may also be transferred readily to and from the Salpa.

The building contains two large laboratories, one for general biological work and one for physiological research, and two smaller general-purpose laboratories (Fig. 5). Fluorescent overhead lights assure adequate illumination. Four to six investigators may be conveniently located in each of the larger laboratories and two in each of the smaller laboratories. In addition to the laboratories there are a work shop, a darkroom, three storerooms, a collection room, and a long concrete lanai on which the aquarium tables are located, thus keeping the sea water out of the laboratories proper. The remainder of the laboratory building consists of living quarters with two large bedrooms, one large dormitory, a kitchen, a combination dining and living room, and bathrooms.

Additional living quarters are located in a second building. These consist of two large bedrooms, one smaller bedroom, bathroom, and living quarters for the caretaker. An electrically operated marine railway which can handle all the smaller craft, and a large storage house for pond screens and other large equipment, complete the present plant.

Laboratory equipment: Running sea water with a salinity of about 35 to 36 parts per thousand is distributed to both the large outdoor aquaria and to the smaller salt-water 


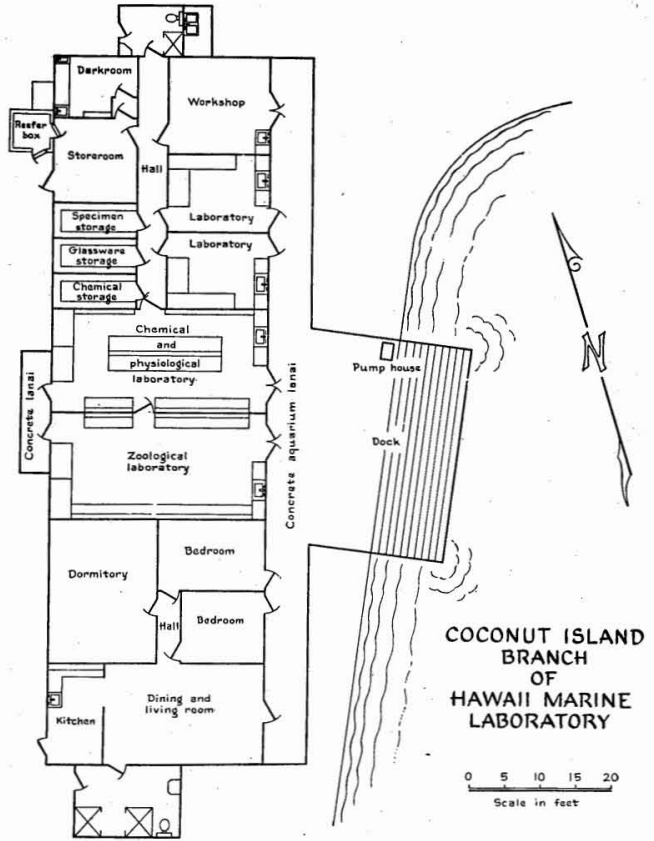

Fig. 3. Floor plan of the laboratory building and dock. tables on the lanai outside the laboratories. Pumps and motors are arranged in duplicate for each system, with a timer switch which automatically alternates the units. There is no storage or recirculation of sea water, but rather a continuous pumping mechanism. The large pumps are made of cast iron while the lines and valves are of transite, antimonyfree lead, and hard rubber. The unit supplying sea water to the smaller laboratory aquaria consists of stainless steel pumps, lead pipes, and hard rubber cocks. The sea water delivered is thus free from contaminants and suitable for the most critical embryological studies. The six large tidal ponds provide unusual space for holding live material, either of small or large size.

Laboratories are supplied with hot and cold running fresh water, 110 - to 115 -volt alternating current, and bottled-gas outlets. Vacuum and pressure are achieved by portable pump

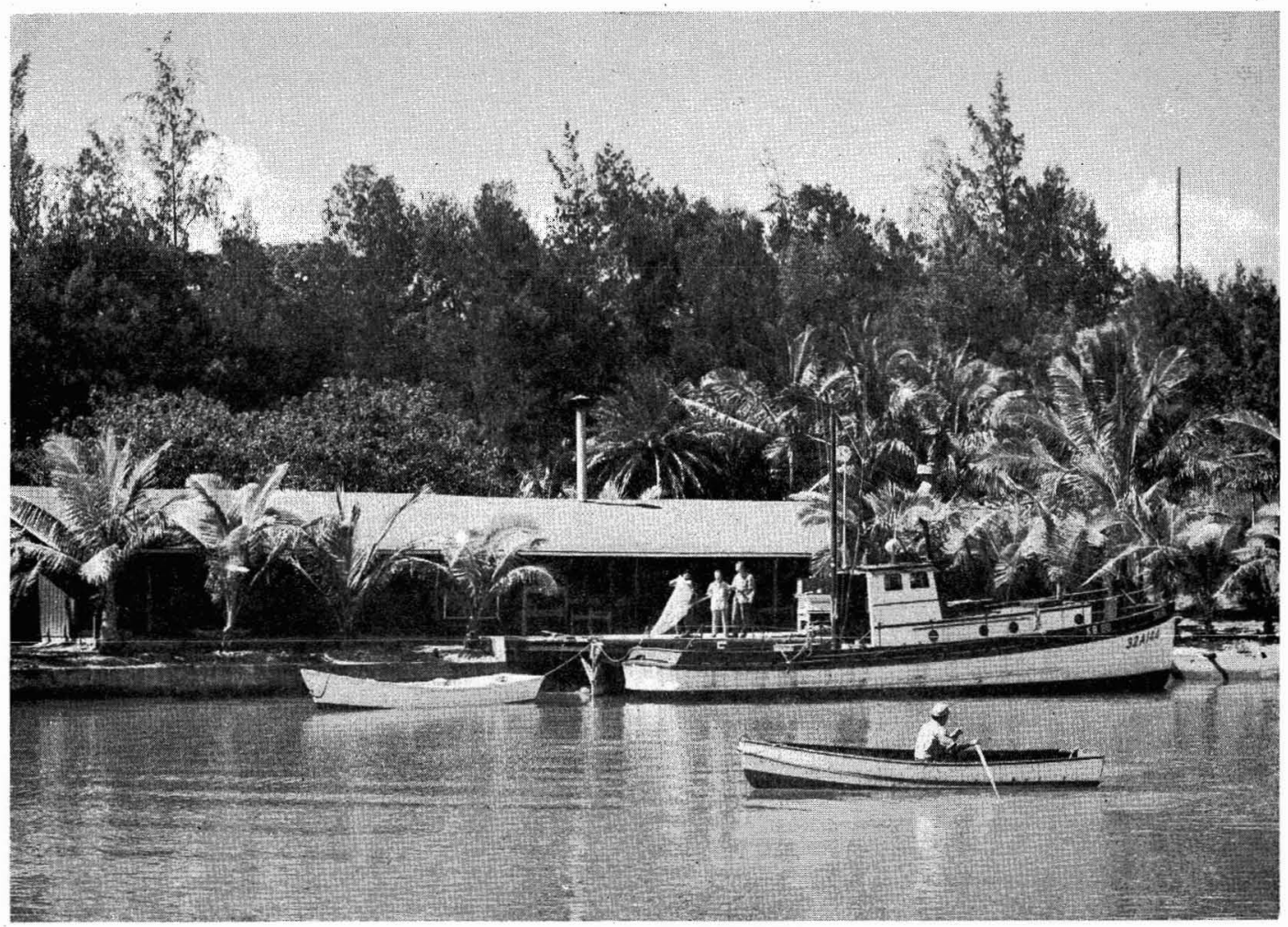

Fig. 4. View of the laboratory building. 


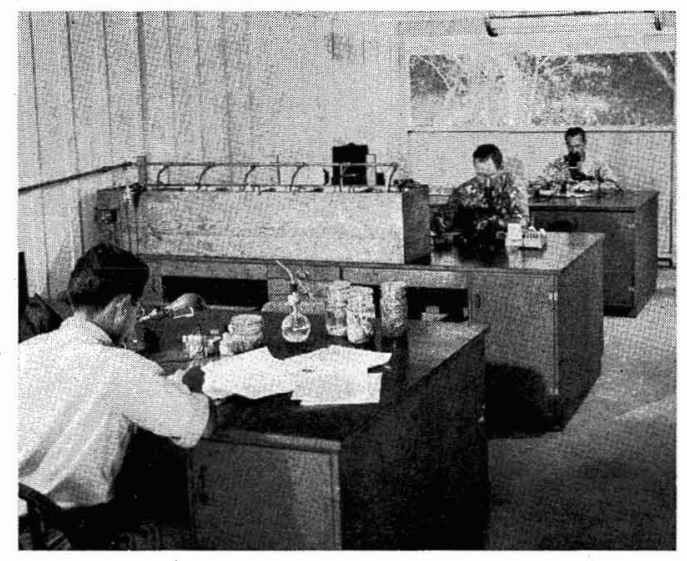

FIG. 5. Interior of a biology laboratory.

units. Direct current may be supplied by batteries or by an a.c.-d.c. converter.

Refrigeration in the laboratory consists of a deep-freeze unit, a 150-cubic foot reefer box, and electric household-type refrigerators.

Small stocks of routine glassware and reagents are maintained at the laboratory. Certain equipment such as $p \mathrm{H}$ meters, colorimeters, Warburg-Barcroft apparatus, VanSlyke apparatus, cathode tay oscilloscope, and other physiological equipment, microscopes, microtomes, balances, cameras, and virtually any other needed item will be supplied by the University from its main campus when the need for them arises. All investigators, however, are requested to submit a detailed list of their needs so that they may be advised of what the Laboratory is in a position to supply.

Field equipment: The opportunities for investigators to conduct research in the field and to observe marine species in their natural environment constitute one of the chief attractions of the Laboratory, and every effort is made to assist investigators on projects requiring this type of approach.

The field equipment includes the 46-foot research vessel, the Salpa (Fig. 6), which has a live well with circulating sea water and hoisting gear for dredging, hauling plankton nets, and hydrographic work. Gear such as dredges, seines, and nets of various sorts, traps, plankton nets from small to meter-size

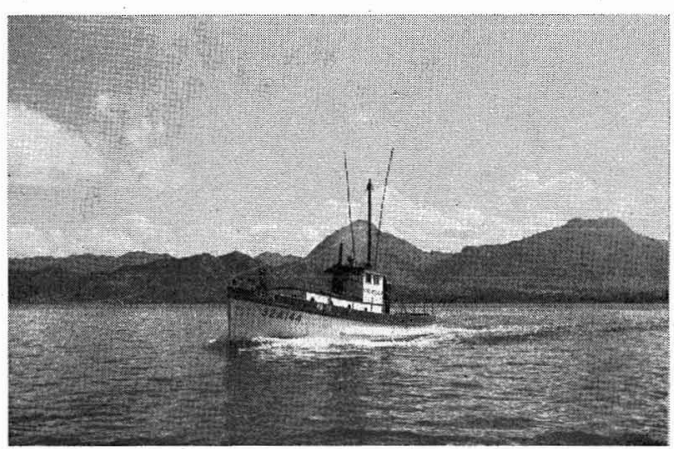

Fig. 6. The Salpa.

openings, Clarke-Bumpus and high-speed quantitative plankton nets, current meters, Nansen bottles with reversing thermometers, bathythermographs, glass-bottom boxes, and diving equipment is available. As with laboratory supplies, investigators are advised to inquire in advance as to their particular requirements.

In cooperation with the Territorial Division of Fish and Game and the Pacific Oceanic Fishery Investigations, larger vessels for work at sea and for deeper dredging are often available to qualified investigators. Such cooperation must be arranged for well in advance.

Library facilities and publications: The proximity of the extensive libraries of the University of Hawaii, Bernice P. Bishop Museum, Hawaiian Sugar Planters' Association Experiment Station, Pineapple Research Institute, and the Pacific Oceanic Fishery Investigations make it unnecessary to maintain a separate library at the Laboratory. At these libraries investigators may secure reference material needed for use at Coconut Island. Microfilm readers are available at the University Library.

The Hawaii Marine Laboratory issues two series of publications. The "Contributions from the Hawaii Marine Laboratory" are technical papers published in suitable journals and are numbered serially. Papers in this series are available to individuals in the fields of their interest, and to institutions which may request individual or all papers of the series. Exchanges are desired. A second series of mimeographed leaflets, entitled "Hawaii 
Marine Laboratory News Circular," is sent to interested persons or institutions.

Housing: Housing for four couples and about ten single investigators is available at the Coconut Island residential area. Since all investigators automatically become temporary (although unpaid) members of the staff of the University, other apartments and houses are frequently available on the main campus. These would be more suitable for investigators with families. The rental fee is nominal, and arrangements should be made several weeks or months in advance. Community kitchen and dining room facilities are available at the Laboratory.

Staff: An advisory board deals with general policies and the distribution of working space if the demand exceeds that available. The Board members are Dr. Albert W. Bellamy, Professor of Zoology, University of California at Los Angeles; Mr. Vernon E. Brock, Director, Territorial Division of Fish and Game; Dr. Robert W. Hiatt, Chairman of the Board and Director of the Laboratory, Professor of Zoology, University of Hawaii; Dr. Carl L. Hubbs, Professor of Zoology, Scripps Institution of Oceanography of the
University of California; Dr. George F. Papenfuss, Associate Professor of Botany, University of California; and Dr. Albert L. Tester, Professor of Zoology, University of Hawaii.

The resident research staff includes Dr. Albert H. Banner, Associate Professor of Zoology (biological oceanography); $\mathrm{Mr}$. Vernon E. Brock, Lecturer in Fishery Biology (ichthyology, fishery biology); Dr. George W. Chu, Associate Professor of Zoology (parasitology); Dr. Maxwell S. Doty, Associate Professor of Botany (marine botany); Dr. William A. Gosline, Associate Professor of Zoology (ichthyology); Dr. Robert W. Hiatt, Professor of Zoology (marine invertebrates, ecology); Dr. Sidney C. Hsiao, Associate Professor of Zoology (experimental embryology, physiology); Dr. John L. Kask, Lecturer in Fishery Biology (fishery biology); Dr. Donald C. Matthews, Associate Professor of Zoology (invertebrate zoology); Mr. O. E. Sette, Lecturer in Fishery Biology (fishery biology); Dr. Albert L. Tester, Professor of Zoology (fishery biology, biometrics); and Dr. Pieter van Weel, Professor of Zoology (comparative physiology). 